Magda Duarte dos Anjos Scherer'

Denise Pires"

Yves Schwartz

\section{Trabalho coletivo: um desafio para a gestão em saúde}

\section{Collective work: a challenge for health management}

\section{RESUMO}

Com base na teorização da ergologia e do processo de trabalho, este ensaio objetiva contribuir para a reflexão acerca do trabalho coletivo em saúde, destacando sua especificidade e as dificuldades de construção e gestão de coletivos de trabalho. Aborda o trabalho como atividade humana que compreende, dialeticamente, a aplicação de um protocolo prescrito e uma perspectiva singular e histórica. O trabalho em saúde envolve uma relação entre sujeitos que agem nas dramáticas do uso de si e que fazem a gestão do seu próprio trabalho; é influenciado pela história das profissões de saúde e pelas determinações macro-políticas. Conclui-se que essa complexidade do trabalho em saúde precisa ser considerada no processo de gestão de equipes/ coletivos profissionais de modo a articular ações que possibilitem implementar um novo projeto de atenção à saúde na perspectiva da integralidade.

DESCRITORES: Trabalho, organização e administração. Satisfação no Emprego. Equipe de Assistência ao Paciente. Recursos Humanos em Saúde. Serviços de Saúde, recursos humanos.

\begin{abstract}
Based on ergology and work process theorization, the study aims to contribute to reflections on health collective work, emphasizing its specificity and difficulties in building and managing groups of workers. It deals with work as a human activity that dialectically comprises the application of a prescribed protocol and a unique and historical perspective. Health work involves a relationship among individuals who act in the drama of using themselves and manage their own work; it is influenced by the history of health professions and macropolitical determinations. In conclusion, this health work complexity needs to be considered in the process of management of professional teams/groups of workers, in a way that actions can interact and enable the implementation of a new health care project in the perspective of comprehensiveness.
\end{abstract}

DESCRIPTORS: Work, organization and administration. Job Satisfaction. Patient Care Team. Health Manpower. Health Services, manpower. 


\section{INTRODUÇÃO}

As formas atuais de organização e de gestão do trabalho continuam repousando, predominantemente, sobre princípios que sacrificam a subjetividade em nome da rentabilidade e da competitividade. Se por um lado aumenta a produtividade, por outro desagrega coletivos e separa o trabalho do conjunto da vida, agravando as patologias decorrentes do trabalho. ${ }^{3}$

Refletir sobre as transformações do trabalho tem implicações políticas e éticas uma vez que as relações e instrumentos utilizados na produção do conhecimento e dos produtos materiais e não materiais não estão separados das escolhas e julgamentos de valor. ${ }^{10}$

Mudanças no trabalho ocorreram ao longo da história da humanidade sob forte determinação econômica. Contudo, apesar da fragmentação do processo e da separação entre concepção e execução, agravados com o taylorismo e o fordismo, os grupos e indivíduos sempre realizaram algum tipo de negociação e de gestão da relação entre contraintes (constrangimentos de dimensão subjetiva e objetiva) e valores. ${ }^{12}$

Assim, considerando-se de um lado, as contraintes institucionais e pessoais, e de outro a especificidade do trabalho em saúde, no exercício profissional, as ações são reconfiguradas permanentemente pelas escolhas cotidianas dos sujeitos. Portanto, para alcançar mudanças no modelo assistencial é preciso considerar essas dimensões que ultrapassam o modelo tradicional prescrito de políticas. Há necessidade da construção de um processo de co-responsabilização entre profissionais, usuários e gestores na definição e realização da atenção à saúde, em que se incluem a gestão e o controle social.

Neste cenário colocam-se como questões o significado de trabalho coletivo e equipe de trabalho e como estes conceitos se aplicam à gestão de coletivos de trabalho em saúde.

O presente artigo, construído a partir da teorização da ergologia e do processo de trabalho, discute trabalho coletivo em saúde e caracteriza suas especificidades e dificuldades de construção e gestão de coletivos de trabalho.

\section{TRABALHO COMO ATIVIDADE HUMANA: CONTRIBUIÇÃO DA ERGOLOGIA}

Considerando-se a heterogeneização e complexificação do trabalho na sociedade atual, um caminho promissor é compreendê-lo como atividade humana. Ao analisar a atividade/ação de trabalho, percebe-se um entrecruzamento de normas antecedentes e tentativas de renormalização na relação com o meio, no qual ocorre um debate permanente de valores, resultando em es- colhas feitas por indivíduos e grupos. No contexto do trabalho stricto sensu, ou seja, atividade remunerada na sociedade de mercado e de direito, as normas antecedentes são tudo que antecipa a atividade de trabalho. As renormalizações resultam de múltiplas gestões de variabilidades impossíveis de serem antecipadas, pois são feitas por seres e grupos sempre singulares e em situações de trabalho, também, singulares. ${ }^{12}$

A gestão, na perspectiva da ergologia, é um fenômeno universal que ultrapassa a dimensão macro-política e a prescrição de atividades e tarefas. Envolve escolhas, arbitragens, hierarquização de atos e objetivos, além de envolver valores que orientam a tomada de decisões pelos trabalhadores no cotidiano.

Ao discutir a complexidade epistemológica da categoria "trabalho", Daniellou estabelece uma analogia com o tear e afirma que "na sua atividade de trabalho, homens e mulheres tecem". ${ }^{2}$ A trama seria os processos técnicos, as propriedades da matéria, os instrumentos, os clientes, as políticas econômicas, as regras formais, o controle das pessoas, entre outros. A urdidura seria a própria história dos indivíduos, o corpo que aprende e envelhece, o pertencimento a grupos sociais que fornecem valores, saberes, regras, projetos, angústias, entre outros. A trama seria o lado visível do trabalho e a urdidura, o menos visível ou invisível. ${ }^{2}$ A dialética do entrecruzamento entre o visível e o invisível, o global e o local, é permeada por debates de normas e valores que geram situações de trabalho relativamente previsíveis e ao mesmo tempo novas e inéditas, pois toda atividade humana integra uma dimensão de transformação. ${ }^{4}$

Para a realização de um trabalho, existe sempre uma prescrição que consiste em objetivos definidos, regras e procedimentos relativos aos resultados esperados e a maneira de obtê-los. A prescrição é feita pela sociedade e pela instituição, mas também pelo próprio trabalhador e pelos colegas de trabalho, individualmente e em grupo. A prescrição não é apenas o oficial, mas também o oficioso, a maneira como os trabalhadores se organizam para fazer ou não o que está prescrito. $\mathrm{O}$ trabalho real corresponde à atividade realizada e também àquilo que é avaliado na incerteza, descartado com pesar ou sofrimento, por meio do debate de normas sempre presente.

A atividade de trabalho "é sempre uma dramática do uso de si." ${ }^{10}$ Nessa dialética de uso de si, o trabalhador faz uso de si mesmo em função do que os outros the demandam e do que ele próprio se demanda, e faz uso dos demais. Esse jogo expressa o coletivo de trabalho.

O uso de si por si e pelos outros manifesta as dimensões de execução e de subjetividade, o trabalhador parcialmente se dá normas, se autolegisla e recria saberes, valores e novas normas, dificultando a gestão. ${ }^{10}$ 
Compreender que o essencial de todo trabalho pode estar na dialética entre trama e urdidura contribui para reconsiderar os conceitos de inovação, rotina e resistência à mudança. As mudanças devem ser apropriadas pelos trabalhadores a partir do seu patrimônio de conhecimentos, de saberes práticos e de valores. ${ }^{12}$

É problemático estabelecer quais as competências apropriadas para o trabalho, a exemplo da área da saúde, em que o objeto é de grande complexidade e as situações de trabalho são difíceis de padronizar. Isso ocorre, em grande parte, porque o processo de cuidar envolve um encontro sempre singular entre sujeitos.

\section{TRABALHO COLETIVO}

No debate contemporâneo sobre o trabalho, Schwartz ${ }^{11}$ considera que nenhuma atividade humana pode ser totalmente padronizada e controlada. Os coletivos de trabalho se transformam acompanhando as mudanças sociais, culturais, econômicas, tecnológicas, entre outras, re-atualizando permanentemente o debate acerca do trabalho e da utilização da força coletiva.

O coletivo prescrito se distingue do coletivo real. As micro-recomposições do coletivo em torno da equipe permitem orientar o processo de trabalho em função de referências e lógicas próprias à atividade na qual as prescrições são reapropriadas. Schwartz ${ }^{11}$ afirma que a busca de eficácia dos coletivos de trabalho nas organizações constitui Entidades Coletivas Relativamente Pertinentes (ECRP). São entidades porque envolvem pessoas, mas as fronteiras do coletivo são invisíveis e variam conforme o conteúdo e o ritmo da atividade de trabalho; as pessoas podem pertencer a serviços diferentes e trabalhar juntas por compartilharem valores. São coletivas porque são vários trabalhadores buscando a eficácia e às vezes eficiência no seu trabalho. São pertinentes para compreender como o trabalho acontece. São relativas porque as fronteiras são variáveis, se formam a partir dos atos de trabalho, em função das pessoas, da necessidade de trabalharem juntas e da história das organizações. ${ }^{11}$

O conceito de ECRP contribui para a compreensão dos processos de cooperação existentes na realização de uma atividade, que são diferentes a cada momento. É pela análise do micro da atividade que se pode identificar as trocas e as ações que tecem a rede relacional do trabalho coletivo. Existem aspectos observáveis e outros invisíveis nos coletivos de uma atividade de trabalho formalizada ou não. O conceito de equipe, compreendido na maioria das vezes como algo estável, é limitado para analisar o trabalho coletivo porque o coletivo se reconstitui conforme a necessidade do trabalho. ${ }^{5}$

A partir de uma representação da atividade, os indivíduos cooperam ou se confrontam, avaliam o que é possível realizar e a composição final será sempre singular. Co- nhecer o trabalho do outro é condição necessária para que uma colaboração se desenvolva. A comunicação, a identificação da presença de diversas lógicas e a compreensão, pelos profissionais, das contraintes das outras profissões, podem contribuir para a resolução das dificuldades de colaboração. A gestão cotidiana de compromissos, implícitos ou explícitos, pode articular as diversas lógicas dos distintos atores.

A construção do coletivo depende da presença de um mínimo de estabilidade e de certa permanência na organização, pois a confiança e a cooperação se constroem com o tempo. A cooperação é fruto da busca do trabalhador pela qualidade do trabalho como uma condição para ter prazer na atividade laboral, saúde mental e construção da sua identidade singular.

Toda organização é permeada por relações de poder e a ética da responsabilidade e da solidariedade é fundamental para orientar ações e construir coletivos. ${ }^{11}$

\section{TRABALHO COLETIVO EM SAÚDE E SUAS MÚLTIPLAS DIMENSÕES}

Os serviços de saúde atendem a necessidades complexas e variáveis e não podem ser totalmente padronizados. Os profissionais precisam de autonomia para traduzir normas gerais a casos particulares, decidir como e qual serviço prestar para atender às necessidades de saúde. ${ }^{4}$

As organizações de saúde dependem do trabalho de profissionais da saúde e de outros grupos de trabalhadores que não são profissionais de saúde, resultando numa heterogeneidade que dificulta a construção do espírito de equipe. ${ }^{9}$ É um contexto de recursos limitados e necessidades sempre múltiplas, ilimitadas e variáveis. O ambiente é propício a conflitos entre atores com diversos interesses, nem sempre convergentes, o que demanda um processo de negociação permanente.

Torna-se um grande desafio à gestão dos serviços de saúde considerar o conjunto de demandas e necessidades, numa ética que contemple os interesses da coletividade e as necessidades de usuários e dos diversos grupos de trabalhadores da saúde.

O trabalho em saúde é marcado pela história das profissões que obtiveram uma definição de seu domínio de competências e atos próprios que pesam sobre a divisão do trabalho e sobre a fronteira entre os grupos.

A complexidade das formas de organização do trabalho coletivo introduzidas pela produção capitalista e suas mudanças recentes, bem como o paradigma positivista e a hegemonia da biomedicina têm influenciado o trabalho em saúde. A fragmentação de atividades dentro de campos profissionais e a influência da gerência científica nos serviços têm resultado em mudanças 
relacionadas ao controle sobre o processo de trabalho e a autonomia, característicos das profissões. ${ }^{9}$

Há consenso na literatura em saúde, em especial no debate brasileiro sobre o Sistema Único de Saúde (SUS), de que é necessário revisar a hegemonia do médico no trabalho em saúde e caminhar no sentido de práticas interdisciplinares para ampliar a qualidade da atenção à saúde.

O trabalho médico e dos demais profissionais de saúde deve ser concebido como parte de uma totalidade complexa e multideterminada. A centralidade do trabalho médico tem sido apontada como um paradoxo, pois tem contribuído tanto para a manutenção de um modelo assistencial descompromissado com o usuário e centrado no procedimento como para construir novas formas de agir em saúde. ${ }^{6}$

No caso brasileiro, mudanças recentes sinalizam possibilidades de práticas mais colaborativas e com impacto positivo no resultado assistencial: a criação do SUS e o investimento na Saúde da Família como estratégia reestruturante do modelo assistencial; os estímulos às mudanças na formação, advindos dos Ministérios da Saúde e da Educação; as experiências de formação de equipes com atuação interdisciplinar nas quais se verifica certa diluição do corporativismo médico e maior valorização das práticas dos diversos profissionais de saúde.

O trabalho em saúde acontece majoritariamente na modalidade de trabalho coletivo multiprofissional e em cooperação, mas geralmente por meio de ações fragmentadas, em que cada área técnica se responsabiliza por uma parte da atividade. ${ }^{9}$

O trabalho da equipe multiprofissional de saúde é um trabalho coletivo marcado por uma relação recíproca entre as múltiplas intervenções técnicas e pela interação dos diferentes profissionais. ${ }^{8}$ Contudo, a multiprofissionalidade não tem garantido respostas adequadas à complexidade das demandas assistenciais. ${ }^{13}$ Essa equipe prescrita é um elemento importante, mas sua definição é insuficiente para compreender as trocas entre as pessoas para a realização da atividade e para torná-la mais eficaz. ${ }^{11} \mathrm{~A}$ atividade de trabalho de uma equipe se integra permanentemente com outros serviços e outras equipes. Existe uma rede relacional mais ou menos informal que se constrói no trabalho coletivo. ${ }^{5}$

No trabalho em saúde, pela sua natureza, as atividades são singularizadas permanentemente, sobretudo nas ações de assistência direta ao usuário, dificultando a aplicação de prescrições, o que favorece a organização das ECRP, que se traduzem por todos os gestos, iniciativas e relações que acontecem sem que haja formalização no organograma e que vão permitir que as técnicas e os procedimentos tenham eficácia. ${ }^{11}$
No desenvolvimento da atividade de trabalho, o profissional procura aqueles com quem possa compartilhar valores e escolhas, que possa confiar e que irão contribuir para atender uma determinada necessidade de saúde, buscando a eficácia.

Um processo de trabalho baseado nos princípios da integralidade, intersetorialidade e interdisciplinaridade amplia as interfaces a gerir e coloca novos desafios no plano das competências. Nesse sentido, os conceitos de Campo (saberes comuns a diversas profissões) e Núcleo (saberes de responsabilidade específica de cada profissão), sugeridos por Campos, ${ }^{1}$ são úteis para articular a necessidade de polivalência e de especialização, e para lidar com a autonomia e definição de responsabilidades.

A gerência é um elemento importante que pode possibilitar que a polivalência, a ajuda-mútua e as trocas não sejam condenadas à semi-clandestinidade, mas patrocinadas por organogramas e gerenciamento sensíveis às exigências de flexibilidade e de renormalização contínuas. ${ }^{11}$

A saúde é atividade de grande complexidade que envolve questões relacionadas à vida e à morte e que tem como objeto de intervenção a saúde e a doença no seu âmbito social. ${ }^{7}$ Essa realidade gera a necessidade de vários conhecimentos e práticas para lidar com sujeitos que têm história de vida singular, "que têm emoções e interesses, que participam de grupos e têm inserção social que lhes dá possibilidades distintas de adoecer e de ter acesso a tratamento". ${ }^{9}$

De certa maneira, sempre há algo de desconhecido no trabalho em saúde, na prescrição do cuidado. Cada projeto vai provocar cooperação e conflitos entre os profissionais, na definição dos problemas prioritários, bem como dos recursos e meios para resolvê-los. Os saberes adquiridos ao longo do processo de formação são necessários para atuar nesse cenário, mas insuficientes. O contexto organizacional e profissional coloca a seguinte questão: como avançar no sentido de um projeto que exige flexibilidade, humildade e construção de campos de conhecimento?

O trabalho em saúde é permeado todo o tempo por práticas multi, pluri e interdisciplinares, conforme os problemas que se colocam, as demandas surgidas e a necessidade de resolução. O tipo da prática depende da complexidade do problema ou da demanda? Problemas simples não demandam intervenções interdisciplinares? Há urgência de eficácia e de eficiência, e para tanto o profissional ou a equipe, dependendo da situação será um ou outro, irá procurar recursos de outras especialidades ou não. Mas essa eficácia e eficiência serão julgadas por ele próprio, pelos seus colegas de trabalho e pelo usuário. 


\section{CONSIDERAÇÕES FINAIS}

A teorização sobre processo de trabalho e ergologia conclui que conhecer o trabalho requer conhecer os sujeitos e o contexto do trabalho. A organização do trabalho, quando especifica os postos, as competências, as qualificações e as relações entre as pessoas produz implicitamente um modelo sobre o que os sujeitos apreendem e pensam sobre si mesmos. Quando a organização diz ao trabalhador que deve se ater ao prescrito, ela interdita formas de conhecimento que poderiam problematizar a questão do trabalho como lugar e momento de produção de eficácia.

A ergologia não negligencia as determinações e constrangimentos macro políticos e econômicos, mas acrescenta que, no exercício das atividades cotidianas os trabalhadores fazem a gestão de si mesmos e de sua relação com os outros participantes de coletivos de trabalho. Levam em consideração as normas prescritas e tecem, entre a trama e a urdidura, permanentes renormalizações.

\section{REFERÊNCIAS}

1. Campos GWS. Saúde pública e saúde coletiva: campo e núcleo de saberes e práticas. Cienc Saude Coletiva. 2000;5(2):219-30. DOI: 10.1590/S141381232000000200002

2. Daniellou F. A ergonomia em busca de seus princípios - debates epistemológicos. Trad.de MIS Betiol. São Paulo: Edgard Blücher; 2004.

3. Dejours C. Intelligence pratique et sagesse pratique: deux dimensions méconnues du travail réel. Educ Perm. 1993;116(3):47-70.

4. Dussault G. A Gestão dos serviços públicos de saúde: características e exigências. Rev Adm Publica. 1992;26(2):8-19.

5. Efros D. Travailler en equipe, de quelle équipe et de quel travail parle-t-on? Soins Rev Ref Infirm. 2004;(49):26-9.

6. Merhy EE. Saúde: a cartografia do trabalho vivo. São Paulo: Hucitec; 2002. (Saúde em Debate, 145).

7. Peduzzi M, Palma JJL. A equipe de Saúde. In: Schraiber LB, Nemes MIB, Mendes-Gonçalves RB,
Apesar dos limites internos e externos à realização do trabalho, é o trabalhador, nas instituições de saúde, no coletivo e na prática cotidiana que desenvolve e sustenta um projeto de ação. E no caso da saúde, o objeto de trabalho é um outro sujeito concreto que influencia, numa relação dialética, o processo de trabalho dos profissionais.

As principais dificuldades de gestão do trabalho coletivo em saúde dizem respeito: à relação entre sujeitos individuais e coletivos; à história das profissões de saúde e o seu exercício no cenário do trabalho coletivo institucionalizado e à complexidade do jogo político e econômico que delimita o cenário das situações de trabalho.

Os trabalhadores de saúde são sujeitos de processos de trabalho que os aproximam e os afastam da crença de que é possível um novo projeto de atenção à saúde que tenha como referência a integralidade da atenção. E para um novo projeto, é preciso tornar-se um agente de mudanças.

organizadores. Saúde do adulto, programas e ações na unidade básica. São Paulo: Hucitec; 2000. p.234-50.

8. Peduzzi M. Equipe multiprofissional de saúde: conceito e tipologia. Rev Saude Publica. 2001;35(1):103-9. DOI: 10.1590/S003489102001000100016

9. Pires D. Reestruturação produtiva e trabalho em saúde. 2,ed. São Paulo: Annablume; 2008.

10. Schwartz Y. Reconnaissances du travail: pour une approche ergologique. Paris: PUF; 1998.

11. Schwartz Y. Le paradigme ergologique ou un métier de philosophe. Toulouse: Octares editions; 2000.

12. Schwartz Y. La conceptualisation du travail, le visible et l'invisible: L'omme et la société. Rev Int Sci Soc. 2004;2(152):47-77.

13. Silva NEK, Oliveira LA, Figueiredo WS, Landroni MAS, Waldman CCS, Ayres JRCM. Limites do trabalho multiprofissional: estudo de caso dos centros de referência para DST/Aids. Rev Saude Publica. 2002;36(4 Supl):108-16. DOI: 10.1590/S003489102002000500015 